\title{
An investigation into the management of deep-fat frying oils used in a sample of Merseyside food outlets
}

\author{
Leo Stevenson, Andrea Tierney, Amanda Wright and Alena Kusnierikova \\ Liverpool John Moores University, Liverpool, UK
}

\begin{abstract}
Although a range of oils with different physical and chemical properties are used in the commercial frying of foods, all these oils undergo marked changes during frying as the oil is continuously and repeatedly used at elevated temperatures $\left(160-180^{\circ} \mathrm{C}\right)$ in the presence of air and moisture. This treatment causes thermal and oxidative changes in the oil, including the formation of volatile and non-volatile decomposition products ${ }^{(1)}$.

From a nutritional perspective, it is the non-volatile degradation products of frying oils (as a result of the thermal oxidation and polymerisation of unsaturated fatty acids) that are the most relevant; since they remain in the oil, are absorbed into fried foods and are subsequently ingested ${ }^{(2,3)}$. Diets high in lipid oxidation and polymerisation products (found in used cooking and frying oils) are associated with cellular alteration and reduced endothelial function, as well as LDL oxidation ${ }^{(4-6)}$.

The overall aim of the present study was to assess how well the deep-fat frying process is currently understood and managed in a sample of Merseyside take-away food and catering establishments providing foods that have been deep-fat fried.

A semi-structured questionnaire was designed to collect information related to deep-fat frying and the handling of deep-fat-fried foods. Data was collected from 153 respondents from 209 premises approached in a convenience sample of food outlets in the Merseyside area. Premises included fish and chip shops and take-away fast-food outlets (36\%); cafés and restaurants $(36 \%)$ and public houses (15\%) that all served deep-fat fried foods.

Only $13 \%$ of respondents had received any formal training that included frying and frying oil management (e.g. National Vocational Qualifications in catering). Only $32 \%$ of respondents were able to identify a suitable holding temperature and $<10 \%(7.2 \%)$ of respondents could correctly identify an appropriate food:fat or oil.

Approximately $10 \%(9.6 \%)$ of respondents in the study claimed to be using discarded frying fat or oil as an ingredient in other foods, with the percentage of take-away food outlets reporting re-using discarded frying fats and oils as a food ingredient being significantly higher $(25.6 ; P<0.05)$.

The present work suggests that there is a need for simple, clear and specific frying-related education and training for staff who deep-fat fry foods. There is also a need to develop: clear guidelines on frying fat and oil quality standards; simple and convenient-to-use objective measurements of frying oil quality; new legislation to enforce frying fat and oil quality standards, or better adoption of existing food safety management systems (e.g. hazard analysis and critical control points ${ }^{(7)}$ ) to include deep-fat frying risk and hazard analysis. Further research into the chemical quality of used frying fats and oils and the potential nutritional consequences of uptake of such fats and oils and derivative compounds into fried foods is also needed.
\end{abstract}

1. Moreira RG, Castell-Perez ME \& Barrufet MA (1999) Deep Fat Frying, 2nd ed., New York: Aspen Publishers Inc.

2. Alexander JC (1978) J Am Chem Soc 55, 711-717.

3. Saguy S \& Dana D (2003) J Food Eng 56, 143-152.

4. Williams MJA, Sutherland WHF, McCormick MP, De Jong SA, Walker J \& Wilkins GT (1999) J Am Coll Cardiol 33, 1050-1055.

5. Andrikopoulos KN, Antonopoulou S \& Kaliora AC (2002) Lebenson Wiss Technol 35, 479-484.

6. Indart A, Viana M, Grootveld MC, Silwood CJ, Sanchez-Vera I \& Bon B (2002) Free Radic Res 36, 1051-1058.

7. US Department of Agriculture (2008) HACCP. http://fsrio.nal.usda.gov/document_fsheet.php?product_id=155. 